\title{
¿Autoritarismo subnacional en países unitarios? Una reflexión sobre dos casos peruanos (2006-2014) ${ }^{+}$
}

\author{
ROSA ARÉVALO* \\ Pontificia Universidad Católica del Perú \\ rosa.arevalo@pucp.pe \\ PAOLO SOSA VILLAGARCIA** \\ Instituto de Estudios Peruanos \\ paolo.sosa@gmail.com \\ https://doi.org/10.18800/rcpg.201602.006
}

\section{RESUMEN}

El objetivo del artículo es comprender los alcances conceptuales y explicativos de la literatura sobre autoritarismos subnacionales — generada en casos federales - para países con configuraciones unitarias. De esta manera, se analizan los casos de Áncash y Loreto (2006-2014); cuyos gobernadores regionales estuvieron involucrados en escándalos de corrupción y autoritarismo, y, posteriormente, fueron removidos de sus cargos antes de culminar su mandato. Proponemos que la forma como aparecen estos fenómenos en países unitarios demanda mayor atención sobre su carácter sistémico antes que observar la formación de regímenes diferenciados. Para ello, complementamos la literatura previa centrando el análisis tanto en la competencia electoral (acceso al poder) como en las dinámicas de gobierno (ejercicio del poder). Argumentamos que, en un contexto de debilidad partidaria, la divergencia entre el tejido social subnacional y los tipos de actores dominantes en este escenario constituyen sistemas políticos diferentes, condicionando las estrategias de gobierno y sus relaciones con otros actores.

Palabras clave: gobierno, democracia, corrupción, política subnacional, Perú, Áncash, Loreto.

Sub-national authoritarianism in unitary countries? A report on two Peruvian cases (2006-2014)

\section{Abstract}

The paper's objective is to understand the conceptual and explanatory scope of subnational authoritarianism literature - generated in federal cases - for unitary-system countries. In this way, we analyze the cases of Áncash and Loreto (2006-2014). In these cases, governors were

\footnotetext{
* Licenciada en Ciencia Política y Gobierno por la Pontificia Universidad Católica del Perú (PUCP) y miembro del Grupo de Investigación de Política Subnacional (GIPSN-PUCP).

** Licenciado en Ciencia Política y Gobierno por la Pontificia Universidad Católica del Perú (PUCP). Miembro del Grupo de Investigación de Política Subnacional (GIPSN-PUCP).

+ Recibido el 25 de enero de 2017; aceptado 9 de marzo de 2017.
} 
involved on corruption and authoritarianism scandals before being removed from office without completing their term. We propose that the way this phenomenon appears in unitary countries demands greater attention on its systemic character rather than just observing the formation of differentiated regimes. In that way, we complement previous perspectives focusing our analysis in both electoral competition (access to power) and government dynamics (exercise of power). We argue that, in a context of weak political parties, the divergence between the subnational social fabric and the dominant types of actors in these scenarios constitute different political systems, conditioning government strategies and their relations with other actors.

Key words: Government, Democracy, Corruption, Subnational Politics, Peru, Áncash, Loreto. 


\section{INTRODUCCIÓn ${ }^{1}$}

Luego de la caída de Alberto Fujimori, el Perú experimenta su periodo democrático más largo en la historia contemporánea. Dentro de este periodo, la descentralización política y administrativa es una de las reformas estatales más ambiciosas, a pesar de mantener la matriz unitaria del sistema político ${ }^{2}$. De esta manera, a partir del año 2002, cada cuatro años se celebran elecciones para definir a los gobernadores regionales en un contexto partidario heterogéneo y fragmentado (Barrenechea, 2014; Zavaleta, 2014). Durante los últimos ańos, la discusión sobre estas autoridades se incrementó en el debate público debido a la existencia de escándalos de corrupción y, más recientemente, de conductas autoritarias en sus jurisdicciones. Dichas dinámicas pusieron en evidencia que la democratización experimentada en el nivel nacional no había logrado resultados homogéneos en todos los niveles de gobierno a lo largo del territorio ${ }^{3}$.

Esta situación fue recrudeciéndose a partir del año 2014, a puertas del cuarto proceso electoral, con el descubrimiento de "enclaves autoritarios» a nivel subnacional, especialmente luego de la mediatización del asesinato de un político opositor en la región Áncash (Barrenechea y Sosa Villagarcía, 2014; Barrenechea, 2014; Zavaleta, 2014, p. 289; BTI, 2016, p. 6). Es así que, a partir de ese momento, se empezaron a denunciar un número creciente de casos bajo la etiqueta de «autoritarismo subnacional» en regiones donde los gobernadores regionales eran acusados por presuntos delitos de corrupción y/o la alternancia electoral había sido bastante limitada (Ayacucho, Cajamarca, Callao, Cusco, Loreto, Pasco y Tumbes). Así, en 2015, estas denuncias avivaron la discusión mediática y el Congreso de la República respondió con la aprobación de una ley cuyo objetivo central era la prohibición de la reelección de las autoridades regionales ${ }^{4}$.

\footnotetext{
1 Una primera versión de este artículo fue presentada en el VIII Congreso de la Asociación Latinoamericana de Ciencia Política (ALACIP) - Lima 2015, dentro del panel Régimen político y representación subnacional organizado por el Grupo de Investigación Gobiernos y Política Subnacional en América Latina (GOPSAL). Agradecemos a los participantes del panel por los comentarios y sugerencias, así como a la persona encargada por la RCPG para la revisión anónima. Adicionalmente, este trabajo se ha enriquecido por las sugerencias de profesores y colegas en los distintos proyectos que alimentaron esta reflexión, a todos ellos nuestro especial agradecimiento. Los errores persistentes en el documento son, por supuesto, de nuestra entera responsabilidad. Del mismo modo, agradecemos a nuestros anfitriones, informantes y amigos, quienes brindaron su invaluable apoyo para el trabajo de campo en las regiones de estudio.

2 Para ver un balance sobre los avances y limitaciones políticas e institucionales del proceso de descentralización, puede verse Zas Friz (2004); Remy (2010); Palomino et al. (2013) y Zavaleta (2014).

3 Como menciona Gibson, la democratización sustantiva se diferencia de la democratización territorial. En la segunda, la propagación de derechos y prácticas democráticas no se da necesariamente por todos los niveles de gobierno y exhibe variaciones entre las unidades subnacionales (Gibson, 2012, p. 21).

4 Ley 30305 (ver Fuentes legales).
} 
Esta forma de abordar la problemática subnacional, sin embargo, distaba de ser sustancial y, por el contrario, ofrecía una solución efectista a un problema bastante más complejo. Por un lado, el alcance real de la prohibición era bastante cuestionable, especialmente porque las reelecciones representaban un problema cuantitativamente poco significativo. Como demuestran Aragón e Incio (2014), entre 2006 y 2014 las tasas de reelección de gobernadores fueron bastante bajas (Gráfico 1), si bien existe un "pico» en 2010, año en que muchas de estas autoridades habían sido reelectas, comparativamente se trataba de casos aislados que, además, no compartían el mismo desenlace. Por otro lado, los casos señalados como "autoritarismos» variaban considerablemente en las características de los escándalos suscitados (los casos de corrupción no necesariamente son sinónimo de autoritarismo), pero también en los alcances de la concentración de poder y restricción de la dinámica pluralista.

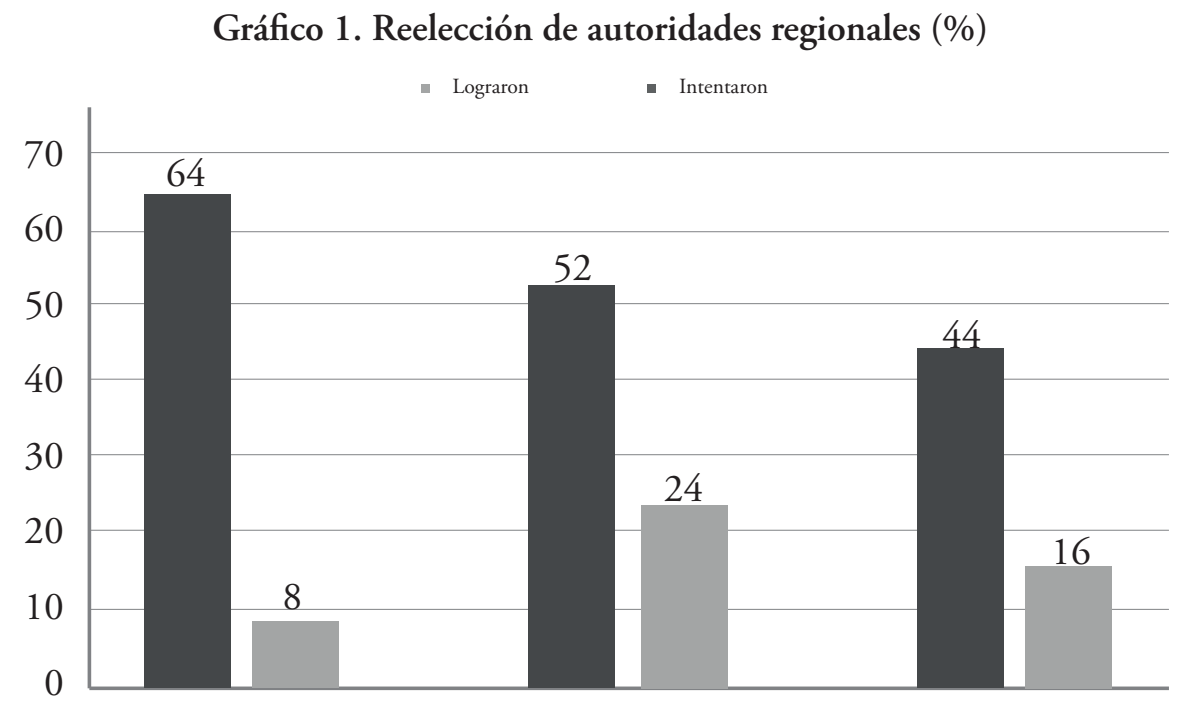

Fuente: Aragón e Incio (2014), con datos de INFOGOB-Jurado Nacional de Elecciones.

¿Cómo estudiar estos casos? Siguiendo los avances teóricos recientes, algunos trabajos enmarcaron el análisis de los casos peruanos tratándolos como regímenes subnacionales forjados, principalmente, por la presencia de recursos económicos extraordinarios como fruto del canon (Cueva et al., 2016). Sin embargo, este concepto y sus teorías explicativas fueron acuñados en trabajos que analizan países con sistemas políticos federales donde los gobiernos subnacionales tienen potestades legislativas y administrativas relativamente más autónomas frente al gobierno central (Behrend, 2012, p. 15; Gibson, 2012), incluyendo áreas 
sensibles como el sistema electoral y los organismos de control político y administrativo. Perú, como hemos señalado, es un país unitario que, a pesar de haber pasado por un proceso de descentralización que sigue en constante construcción, mantiene una serie de instituciones y facultades importantes concentradas en el gobierno nacional, sustancialmente en dichas áreas sensibles 5 .

¿Podemos hablar de autoritarismo subnacional en países unitarios? ¿Qué aporta el caso peruano en este rompecabezas? Más allá de los escándalos mediáticos, importantes trabajos argumentan que sí se pueden encontrar dinámicas de carácter hegemónico o prácticas represivas que alteran las condiciones mínimas del sistema democrático a nivel subnacional. Sin embargo, argumentamos que centrar el tratamiento de estos casos en las características del régimen, usualmente orientado a la competencia electoral, no nos permite concentrarnos en las características sistémicas que lo articulan. Por ello, siguiendo la obra de Guillermo O'Donnell, proponemos que debemos observar la democracia subnacional como un sistema complejo en el que importan tanto las «reglas de juego» para la competencia política netamente electoral, pero también el sistema de normas e instituciones que permiten el pluralismo y previenen la concentración de poder en la dinámica gubernamental.

Por este motivo, consideramos que la literatura sobre autoritarismos subnacionales es útil para identificar y rastrear condiciones relevantes que explican potencialmente las variaciones en las dinámicas subnacionales. Sin embargo, sostenemos que el uso del concepto «autoritarismo subnacional», y las categorías que se desprenden del mismo, no solo pueden ser problemáticas por las complicaciones del «estiramiento conceptual» (Sartori, 2011), sino también por su propia perspectiva de enfoque. Por un lado, su atractivo teórico puede llevarnos a elaborar explicaciones complejas para expresiones sintomáticas antes que para el fenómeno de interés. Por otro lado, y con relación a lo anterior, el creciente interés en este tipo de literatura puede llevar al acomodamiento o confusión de problemas de gobernabilidad y corrupción con la instauración de regímenes diferenciados.

Tomando en cuenta ambas advertencias, el presente artículo busca explorar dos dinámicas regionales donde se llamó la atención sobre la configuración de este tipo de sistemas aparentemente anómalos, para comprender los alcances conceptuales y explicativos de la literatura para este fenómeno. De esta manera, el presente artículo utiliza los casos de Áncash, bajo el gobierno de César Álvarez, y Loreto, bajo el gobierno de Yván Vásquez. En ambos casos los gobernadores

\footnotetext{
5 De hecho, en los últimos ańos, los gobiernos centrales han recentralizado en la práctica algunas de las facultades delegadas a los gobiernos subnacionales debido a conflictos por el extractivismo y otras actividades (Eaton, 2015).
} 
permanecieron en el cargo por dos periodos (2006-2010, 2010-2014), estuvieron involucrados en denuncias por corrupción y autoritarismo, y, posteriormente, fueron removidos de sus cargos antes de culminar su mandato. Este análisis se centra en la competencia electoral y acceso al poder, así como en el ejercicio del poder y sus dinámicas de gobierno (Mazzuca, 2007).

La información recopilada para el análisis de ambos casos ha sido producto del trabajo de campo que permitió entrevistar a más de una veintena de actores regionales oficialistas y opositores, el análisis de documentos oficiales, manifiestos políticos y periódicos locales, y la observación no participante ${ }^{6}$.

Esto nos permite ver que, más allá de las aparentes similitudes, ambos gobiernos se desarrollaron en sistemas políticos y condiciones de gobierno muy diferentes. En Áncash, estamos frente a un caso que, en efecto, logra acercarse a un régimen autoritario subnacional dentro de los cánones de la literatura sobre el tema; sin embargo, como veremos, esta caracterización es un síntoma de un problema sistémico mayor, determinado por la inestabilidad de la oferta política y el débil tejido social regional. Por otro lado, el caso de Loreto ilustra problemas de gobernabilidad y corrupción que fácilmente pueden confundirse con un régimen autoritario subnacional, característica que dista de ser aplicable, al menos en el periodo estudiado.

Por un lado, el gobernador de Áncash, César Álvarez, desplegó estrategias no convencionales que le permitieron mantener estabilidad en su gobierno para enfrentar la precariedad de su organización política. Estas estrategias se desarrollaron aprovechando el contexto económico favorable y la relativa ausencia de coaliciones sociales y económicas con interés en competir por dichos recursos. En Loreto, por otro lado, el gobernador logró articular inicialmente una coalición de gobierno con políticos locales y grupos de interés empresarial en un contexto económico favorable, sin embargo, los conflictos entre estos grupos devinieron en un escenario de tensión que suscitó respuestas autoritarias por parte del gobierno. De esta manera, observamos que el gobierno logró cooptar a

\footnotetext{
6 El método de comparación responde a la perspectiva subnacional establecida por Snyder (2001), mientras que la estrategia de recolección de información en ambos casos refleja lo que Kapiszewski et al. (2015) denominan "estrategias intensivas in-situ» y análisis de documentos en el campo. En Áncash, el trabajo de campo fue desarrollado en el marco de la tesis de licenciatura de Arévalo (2014) en la Pontificia Universidad Católica del Perú, así como de proyectos de investigación posteriores. En Loreto, el trabajo de campo se desarrolló paralelamente a distintos proyectos de Sosa Villagarcia articulados en el Instituto de Estudios Peruanos, así como en el marco del estudio de base para el proyecto "Lucha contra la influencia de los intereses ilegales en los procesos políticos del Perú», promovido por IDEA Internacional. Es importante mencionar que, en el caso de Áncash, la primera parte del trabajo de campo tuvo lugar cuando Álvarez aún era gobernador regional, las siguientes aproximaciones se dieron luego de la captura de Álvarez y otros veintiocho actores involucrados. En el caso de Loreto, por otro lado, todas las experiencias de campo se desarrollaron luego de la captura de Vásquez.
} 
la sociedad y establecer un enclave claramente autoritario hasta la intervención de las instituciones nacionales en el primer caso, mientras que en el segundo, las tensiones entre el gobierno y sus aliados originales motivaron un escenario de desestabilización mediante denuncias de corrupción, donde la respuesta autoritaria acelera la caída del mismo y no logra constituirse como enclave.

Teóricamente, en un régimen autoritario deben existir reglas formales e informales que empañan la competencia política, el acceso a información o la violación a los derechos civiles básicos. En estos casos podemos ver varias de estas características, pero, a diferencia de la literatura federal, las condiciones propias para mantenerse en el poder o controlar efectivamente instituciones dentro de su jurisdicción son bastante más limitadas, aún en el caso extremo de Áncash. Por este motivo, las relaciones con el nivel de gobierno nacional son importantes, situación que aplica también para asegurar el acceso a los recursos públicos que, en última instancia, dependen del Ministerio de Economía y Finanzas ${ }^{7}$. De esta manera, la dinámica de dominación regional en estos casos pasa por la existencia o deterioro de acuerdos y redes de influencia volátiles ${ }^{8}$ que ofrecen diferentes recursos políticos, sociales y económicos para los gobernadores, tales como el acceso a medios de comunicación o la disposición de capital humano para desarrollar actividad proselitista o de amedrentamiento.

\section{1. ¿AUTORITARISMOS SUBNACIONALES O SISTEMAS POLÍTICOS INESTABLES?}

Desde que Guillermo O’Donnell (1999) planteó la metáfora de las «zonas marrones», la ciencia política ha avanzado sustancialmente en el estudio de las dinámicas que se enmarcan en estos espacios territoriales, así como de sus efectos para la democracia. De esta manera, la literatura sobre los autoritarismos subnacionales ha hecho contribuciones importantes a la forma cómo pensamos las dinámicas territoriales de gobierno, pero también a las limitaciones de los procesos de democratización en América Latina y otras regiones. Hoy queda

\footnotetext{
7 Ambas regiones se beneficiaron por los recursos extraordinarios provenientes del canon de actividades extractivas, situación que cambió debido al cambio en las condiciones del mercado internacional, pero también debido a una reducción del presupuesto desde el gobierno central. Según los datos recopilados por el Grupo Propuesta Ciudadana (2016), durante los años de mayor bonanza, Áncash fue la región minera más importante (17\% del total del valor de la producción), mientras que Loreto fue la tercera más importante en términos hidrocarburíferos (14\% del valor de la producción). No obstante, la experiencia histórica con este tipo de presupuesto extraordinario y la proporción de su «inyección» son divergentes. En el caso de Loreto, la experiencia con la actividad extractiva es más larga y el incremento de los recursos es más progresivo, mientras que en Áncash este es un fenómeno muy reciente y la actividad minera condiciona un ciclo de bonanza más agresivo.

8 En ese sentido, es importante tomar en cuenta que los escándalos en Áncash detonaron las investigaciones de parte de los medios y el Estado a varios otros gobiernos regionales, situación que, como en un efecto dominó, motivó la caída de varios de los mismos, haciendo evidentes las deficiencias de la democracia peruana a nivel subnacional.
} 
claro que los procesos de democratización nacionales iniciados en la década de 1980 son, en muchos países, territorialmente heterogéneos (Behrend, 2012, p. 15). Sin embargo, buena parte de esta producción académica adolece de dos problemas fundamentales.

El primer problema es que las investigaciones se han concentrado mayoritariamente en casos enmarcados en sistemas políticos federales, donde los gobiernos subnacionales son relativamente más autónomos y, por lo tanto, las dinámicas de concentración de poder e impunidad frente a los abusos discurren en márgenes más amplios que en países unitarios. De esta manera, la discusión conceptual ha sido relegada a un segundo plano por motivos teóricos y metodológicos más interesados en las explicaciones a estos fenómenos que a su comprensión como tales'. El segundo problema es que la literatura se ha concentrado, sobre todo, en comprender las condiciones que permiten la supervivencia de estos enclaves autoritarios aún después del proceso de democratización nacional. Esta atención en las posibilidades de «democratización» supone una discusión menos sofisticada sobre las condiciones que permiten el surgimiento o recrudecimiento de las prácticas capaces de constituir nuevos autoritarismos subnacionales. En ese sentido, el objetivo de este artículo es analizar el alcance conceptual de esta literatura para comprender estas configuraciones en un país unitario como el Perú, poniendo especial énfasis en las condiciones que nos ayudan a comprender su reciente constitución.

¿Debemos dejar de hablar de «autoritarismos subnacionales» cuando nos enfrentamos a casos enmarcados en sistemas unitarios? La respuesta a esta interrogante depende de lo que comprenda dicha categoría. Lo que proponemos es que las características propias de los países unitarios demandan que retomemos la advertencia original planteada por O’Donnell y miremos a estos enclaves como sistemas complejos, y no tomemos en cuenta solamente la dimensión del régimen político, sino también la dimensión «estatal» (O’Donnell, 1999, 2004 y 2007). Es cierto que los enclaves autoritarios pueden llegar a constituir regímenes políticos diferenciables en el plano de las reglas informales, sin embargo, al menos en la experiencia peruana, estos son casos excepcionales, la punta del iceberg de una problemática más sistémica, que raras veces trasciende a tales niveles. Esto no los excluye como autoritarismos subnacionales, por supuesto, sobre todo si tomamos en cuenta que lo democrático y autoritario no son características exclusivas del régimen, sino también del Estado en su dimensión

\footnotetext{
9 Aún en los casos teóricamente más sofisticados, esto es especialmente problemático en lo que refiere a la congruencia entre las categorías usadas, producidas para fenómenos de nivel nacional, y las complejidades que las unidades subnacionales suponen.
} 
institucional — formal e informal — y gubernamental, puesto que ambas configuran y resguardan los derechos relacionados al correcto funcionamiento del sistema democrático (O’Donnell, 1999 y 2007; Mazzuca, 2007) ${ }^{10}$.

Esto es importante porque gran parte de la literatura está concentrada en la «yuxtaposición de regímenes» entre los distintos niveles (Gibson, 2012; Gervasoni, 2016) ${ }^{11}$, mientras que sus críticos se enfocan más bien en «dinámicas de gobierno», caracterizadas como «iliberales» (Behrend y Whitehead, 2016). La discusión fundamental, sin embargo, está en el núcleo de las definiciones usadas ( «régimen político») y sus implicancias, especialmente en países unitarios donde los límites del poder regional son más mediatos que en los países federales. Entonces, es importante centrar nuestra atención en que un sistema democrático está "caracterizado por el hecho que no existe un poder ni en el Estado ni en el régimen (ni, en ese sentido, en la sociedad) que sea de legibus solutus» (O’Donnnell, 2007, p. 33), es decir, que esté por encima o fuera del alcance de dichas reglas. Esto nos permite mirar el fenómeno en su complejidad pero sin forzar el término. Un enclave autoritario en un país unitario nos fuerza a detenernos en las relaciones — reglamentadas o no por el Estado- que constituyen las dinámicas de interacción cotidianas entre el gobierno y sus opositores, antes que solo en las relaciones involucradas en las dinámicas de competencia ${ }^{12}$.

Por otro lado, las aproximaciones sobre los orígenes de estos escenarios son variadas. Behrend (2012) resume estas explicaciones en cinco condiciones fundamentales: (1) relaciones intergubernamentales, (2) renta y recursos fiscales, (3) reglas electorales y sistemas de partidos, (4) formación de coaliciones legislativas y (6) estructuras de control de las élites locales. En ese sentido, Cueva et al. (2016) clasifican convenientemente estas explicaciones en tres grandes grupos. Primero, las explicaciones que priorizan factores exógenos a la dinámica subnacional (interdependencia con la política nacional, teorías rentistas y diseños institucionales). En segundo lugar, aquellas que priorizan factores endógenos como las dinámicas sociales, económicas y políticas propias de la unidad analizada (modernización, patrimonialismo, relaciones entre élites). Y, finalmente, los modelos mixtos atienden a la complejidad de los fenómenos y las características de dependencia, mezclando ambos tipos de factores. Desde la aproximación

\footnotetext{
10 O’Donnell (1999, pp. 141-142) agrega que en un contexto autoritario no existe un sistema legal o, de existir, no es efectivo o está subordinado a normas secretas y/o al capricho de los gobernantes, lo cual afecta la legalidad estatal y la textura del orden impuesto sobre un territorio.

11 Una interesante discusión del uso del concepto puede ser revisada en Cueva et al. 2016.

12 Esta es una característica ya advertida en la caracterización de las «zonas marrones», donde la dimensión estatal y el régimen político confluyen en su configuración (O’Donnell, 1999, p. 169).
} 
antes señalada, nosotros argumentamos que muchas de estas condiciones pueden verse reflejadas en el caso peruano, no obstante, la diferencia entre el tejido social y los tipos de actores dominantes constituyen sistemas políticos diferentes y condicionan las estrategias de gobierno y sus relaciones con la oposición.

\section{2. ÁNCASH: UN GOBIERNO SIN COALICIONES}

El 14 de marzo de 2014, Ezequiel Nolasco, ex consejero regional de Áncash y precandidato a la gobernación regional, fue asesinado por un sicario en la ciudad de Huacho, mientras viajaba de Lima hacia Chimbote (El Comercio, 2014a). No era la primera vez que se atentaba contra la vida de Nolasco, u otro político regional. En julio de 2010, por ejemplo, Nolasco sobrevivió a un ataque en su hogar tras haber recibido amenazas anónimas ${ }^{13}$, mientras que José Luis Sánchez Milla, vicegobernador regional, murió tras recibir una bala en la pierna en circunstancias que aún son motivo de investigación (El Comercio, 2010; Alcántara, 2015). Sin embargo, la muerte de Nolasco resonó significativamente en la esfera política nacional, y concitó la atención de los medios peruanos e internacionales interesados en las motivaciones políticas de su asesinato, encuadrando este episodio como la evidencia característica de un régimen autoritario subnacional ${ }^{14}$.

Semanas después, el gobernador regional, César Álvarez, fue implicado judicialmente en el asesinato de Nolasco, así como en las investigaciones por el caso "La Centralita», nombre con el que se conocía a un establecimiento que funcionaba en Chimbote. En este espacio, se presume que agentes del gobierno regional realizaban operaciones de espionaje telefónico a los opositores de Álvarez, asî como también se habrían efectuado pagos a diferentes autoridades regionales y periodistas para el blindaje político y judicial del exgobernador regional (Arévalo, 2015). Un tipo de dinámica que, una vez conocida, remitió rápidamente al imaginario colectivo del aparato montesinista de la década de 1990.

No obstante, Álvarez fue electo y pudo gobernar en Áncash durante dos periodos (2006-2014), sin que ninguna de estas prácticas fuera conocida o

\footnotetext{
13 En ese incidente Nolasco fue herido de gravedad, mientras que su hijo político falleció por un impacto de bala en la cabeza (La República, 2010).

14 El diario Correo, en su edición local de Chimbote, publicó una entrevista a Steven Levitsky, titulada «En Áncash la democracia ya no existe» (Cardoza, 2014), nota que llegó a la difusión nacional, siendo reproducida en algunos medios escritos impresos y virtuales de la capital, y, posteriormente, el caso fue abordado por diferentes medios televisivos nacionales. A nivel internacional, The New York Times (2014) y The Wall Street Journal (2014) hicieron eco del asesinato de Nolasco y la existencia de una «mini dictadura» en Áncash, noticia que llamó la atención de otros medios de alcance global. De hecho, la nota, originalmente escrita por la agencia The Associated Press, incluye la reacción del politólogo Edward L. Gibson, uno de los investigadores más importantes en este campo, quien indicó que Álvarez había «ido demasiado lejos», en comparación con los casos estudiados.
} 
tomada seriamente por las instituciones pertinentes, especialmente en el nivel central, aun cuando muchas de ellas ya habían sido judicializadas en instancias regionales. Uno de los puntos más sugerentes es que Álvarez alcanzó la presidencia regional sin haber consolidado una alianza electoral con algún otro grupo político en la región debido, en gran medida, a la crisis política que la región estaba atravesando, puesto que su predecesor, el aprista Freddy Ghilardi, enfrentaba acusaciones por supuestos actos de corrupción. Aun cuando los procesos judiciales no encontraron cargos sancionables, el prestigio que el partido tenía históricamente en la región se fue deteriorando. En consecuencia, Álvarez es electo tras derrotar a las listas del Partido Aprista y de "Rio Caudaloso», las principales en la región en ese entonces.

Al llegar al poder, este escenario de desprestigio limitó las capacidades de armar una coalición de gobierno con las fuerzas derrotadas. Por lo tanto, Álvarez se vio en la necesidad de elaborar otro tipo de estrategia que le permitiese contar con el apoyo tanto de la sociedad como de los demás organismos estatales de la región. Sin aliados y al frente de una organización política endeble, el gobierno recurrió al uso sistemático de prácticas clientelares para captar apoyo de sectores vulnerables, pero también a la represión y amedrentamiento de los grupos opositores. Para fortuna de la gestión, el canon proveniente de la minería y, en menor medida, de la actividad pesquera ofrecía una base económica auspiciosa para el gobierno regional y permitió el financiamiento de gran parte de los proyectos y obras realizadas por el gobierno regional. De hecho, en este escenario presupuestario resalta que el Ministerio de Economía y Finanzas (MEF) premió a la región consecutivamente, desde el ańo 2012, como la región que hizo más efectivo su gasto público ${ }^{15}$.

Sin embargo, las fuentes consultadas indican que esta bonanza presupuestaria también explica el sustento económico de las prácticas clientelares desplegadas por el gobierno, especialmente extendidas durante los contextos electorales (Arévalo, 2015). Esto contribuyó al fortalecimiento de la organización política Cuenta Conmigo, y el incremento de sus comandos ${ }^{16}$. De esta manera, el equipo de campaña podía distribuir bienes con el objetivo de captar la atención de los electores y convencerlos de la viabilidad de reelección, una práctica muy

\footnotetext{
15 De hecho, el gobierno regional «donó» al Ministerio del Interior equipos policiales durante una ceremonia en julio de 2012, en presencia de Álvarez. Esa ceremonia se desarrolló cuando en la región ya se conocía de los malos manejos en la administración pública. Irónicamente, estos equipos luego serían investigados por sobrevaloración (Perú21, 2012).

16 Los comandos son el grupo de personas que conformaban o eran simpatizantes del Movimiento Independiente Cuenta Conmigo de Álvarez, y fueron parte fundamental de su maquinaria política. Asimismo, tenían una gran presencia en las diferentes esferas sociales, políticas y económicas de Áncash.
} 
extendida en el país (ver Muñoz, 2014). Sin embargo, es importante resaltar que esta no era solamente una estrategia electoral, sino que sus motivaciones estaban fundamentalmente alineadas con la estrategia del gobierno para mantener el control de la región. Es así que los proyectos y programas implementados por el gobierno regional se enfocaron en brindar beneficios a la población más vulnerable de la región, un sector que carece de servicios básicos y se concentra en la provincia del Santa-Chimbote ${ }^{17}$.

Como hemos señalado, esta estrategia estaba complementada por la cooptación de las pocas organizaciones sociales con el objetivo de neutralizar a cualquier organización que pudiese hacer presión frente a lo ocurrido en la región $^{18}$. Algunos sectores de construcción civil, por ejemplo, se adhirieron a las filas de César Álvarez a través de la entrega de dinero y víveres, sirviendo como una fuerza de amedrentamiento a los líderes opositores. Por este motivo, durante los últimos meses de la gestión de Álvarez era bastante evidente el recelo de la ciudadanía a participar en la esfera pública debido a las represalias que podían esperarse, sobre todo cuando esto implicaba ser vinculado con algún grupo de oposición o de crítica al gobierno regional ${ }^{19}$. Esta situación se acrecentó debido a la conciencia de que los posibles abusos y ataques no serían investigados porque, según las fuerzas opositoras, las autoridades competentes podrían formar parte del aparato encabezado desde el gobierno regional. Es así como los mecanismos autoritarios de bloqueo para la fiscalización, sumado al componente clientelista, debilitaron el pluralismo en la región.

Esto es relevante, debido a que en la región era conocido que, luego de dos periodos, el gobierno de Cuenta Conmigo había logrado articular importantes alianzas regionales y principales durante las diferentes campañas electorales. Algunas de estas redes se habrían construido durante la trayectoria electoral de Álvarez, que se puede rastrear hasta finales de la década de 1990, cuando postula a la alcaldía provincial de Santa, sin mucho éxito. Posteriormente, como puede verse en la Tabla 1, fue candidato al Congreso en varias oportunidades hasta

\footnotetext{
17 Entre estos beneficios destaca el otorgamiento de 300 hectáreas del conocido proyecto Chinecas como terrenos para el establecimiento de viviendas. En estos casos, el gobierno regional reforzaba la relación de dependencia al no otorgar títulos de propiedad. El proyecto especial Chinecas es un proyecto de exportación agroindustrial a cargo del gobierno regional que atraviesa el desierto de los territorios de Chimbote, Nepeña, Casma y Sechin.

18 Ejemplo de este punto fueron el Frente de Defensa y algunos sindicatos, destacando el de Construcción Civil. Algunos sectores en ese gremio, por ejemplo, se adhirieron a las filas de César Álvarez a través de la entrega de dinero y víveres, sirviendo como una fuerza de amedrentamiento a los líderes opositores. De hecho, según las investigaciones judiciales, este grupo estaría implicado en el asesinato de Ezequiel Nolasco (El Comercio, 15/09/2015).

19 Adicionalmente, el incremento de redes criminales y sicariato en esta zona del país explica la facilidad de acceso a mecanismos de extorsión y represión de extrema violencia (ver IDL, 2015).
} 
que en 2006 accedió al gobierno regional ${ }^{20}$. En consecuencia, la existencia de redes nacionales en el legislativo y los órganos de control judicial ${ }^{21}$ explicaría la permanencia de la estrategia desplegada por el gobierno, bloqueando a las investigaciones que venían, por ejemplo, desde la Procuraduría Anticorrupción de la Sub Región Pacífico ${ }^{22}$.

Tabla 1. Trayectoria electoral de César Álvarez

\begin{tabular}{|c|c|c|c|c|c|c|}
\hline Año & $\begin{array}{l}\text { Proceso } \\
\text { electoral }\end{array}$ & $\begin{array}{c}\text { Cargo al que } \\
\text { postuló }\end{array}$ & Organización política & Región & Provincia & Elegido \\
\hline 1998 & $\begin{array}{l}\text { Elecciones } \\
\text { municipales }\end{array}$ & $\begin{array}{c}\text { Alcalde } \\
\text { provincial }\end{array}$ & Cuenta Conmigo & Áncash & Santa & $\mathrm{NO}$ \\
\hline 2000 & $\begin{array}{l}\text { Elecciones } \\
\text { generales }\end{array}$ & Congresista & $\begin{array}{l}\text { Frente Independiente } \\
\text { Moralizador }\end{array}$ & Nación & - & $\mathrm{NO}$ \\
\hline 2001 & $\begin{array}{l}\text { Elecciones } \\
\text { generales }\end{array}$ & Congresista & $\begin{array}{c}\text { Frente Independiente } \\
\text { Moralizador }\end{array}$ & Áncash & - & $\mathrm{NO}$ \\
\hline 2002 & $\begin{array}{l}\text { Elecciones } \\
\text { regionales y } \\
\text { municipales }\end{array}$ & $\begin{array}{c}\text { Alcalde } \\
\text { provincial }\end{array}$ & $\begin{array}{c}\text { Frente Independiente } \\
\text { Moralizador }\end{array}$ & Áncash & Santa & $\mathrm{NO}$ \\
\hline 2006 & $\begin{array}{l}\text { Elecciones } \\
\text { generales }\end{array}$ & Congresista & $\begin{array}{c}\text { Frente Independiente } \\
\text { Moralizador }\end{array}$ & Áncash & - & $\mathrm{NO}$ \\
\hline 2006 & $\begin{array}{l}\text { Elecciones } \\
\text { regionales y } \\
\text { municipales }\end{array}$ & $\begin{array}{l}\text { Presidente } \\
\text { regional }\end{array}$ & $\begin{array}{c}\text { Movimiento Regional } \\
\text { Independiente Cuenta } \\
\text { Conmigo }\end{array}$ & Áncash & - & SÍ \\
\hline 2010 & $\begin{array}{l}\text { Elecciones } \\
\text { regionales y } \\
\text { municipales }\end{array}$ & $\begin{array}{l}\text { Presidente } \\
\text { regional }\end{array}$ & $\begin{array}{l}\text { Movimiento Regional } \\
\text { Independiente Cuenta } \\
\text { Conmigo }\end{array}$ & Áncash & - & Sí \\
\hline
\end{tabular}

Fuente: Infogob, Jurado Nacional de Elecciones. Elaboración propia.

20 En el año 2006, Álvarez estuvo muy cerca de ganar una elección para asumir el cargo de congresista; sin embargo, en un recuento de votos, el APRA lo deja fuera e ingresa a uno de sus partidarios. Según un reportaje del periodista Ricardo Uceda, esto fue visto como un acto «repudiable» en Chimbote (Uceda, 2014), situación que lo favoreció en las siguientes elecciones regionales y municipales (2006-2010).

21 Así, por ejemplo, se señalaba la relación con el partido nacional Solidaridad Nacional y, en específico, con el ex congresista Heriberto Benítez — quien había sido colega de Álvarez en el Congreso entre los años 2001 y 2005 — y Víctor Crisólogo. Más allá de los vínculos políticos, también existen importantes denuncias de sus vínculos con el ex fiscal José Peláez. Además, los opositores denuncian la existencia de nexos en la Contraloría, en la Fiscalía y Ministerio Público, en el Poder Judicial, en el Consejo Nacional de la Magistratura (CNM), en la Policía y en el Congreso. Esto ayudaría a comprender por qué algunos trabajadores de la Contraloría no iniciaron auditorias sobre los gastos ejecutados, avalando un gasto desmedido, improvisado y sin beneficios económicos ni a corto ni a mediano plazo.

22 La región Áncash tiene una dinámica particular al estar repartida en dos grandes secciones geográficas. Si bien la capital de esta es Huaraz, otra importante cuidad, como ya se ha mencionado, es la provincia del Santa, donde también se pueden encontrar instancias de los organismos estatales. 
De esta manera, Álvarez habría logrado establecer importantes conexiones nacionales que podrían blindarlo potencialmente ante cualquier cuestionamiento de sus prácticas políticas en la región. De hecho, según los opositores, la Fiscalía y Ministerio Público nunca tuvieron la capacidad ni la voluntad expresa para investigar a fondo las graves denuncias que se iban declarando ${ }^{23}$. Asimismo, desde el Poder Judicial no se dieron sentencias que hayan culminado con pena privativa de la libertad contra funcionarios que incurrieron en actos de corrupción durante el gobierno de Álvarez. Esta percepción se potenció por la debilidad de algunos organismos públicos en la región que, aunque no estuvieran implicados o relacionados directamente con la gestión, no contribuyeron en la nacionalización de las denuncias por sus propias limitaciones ${ }^{24}$.

En esta dinámica, el gobierno regional de Cuenta Conmigo también pudo inclinar a su favor a los medios de comunicación locales, muchos de los cuales fungieron como aparatos de prensa del gobierno regional, pero también como caja de resonancia de la persecución y deslegitimación de la oposición ${ }^{25}$. Esta situación fue especialmente importante en el segundo periodo de gobierno, cuando Álvarez y sus allegados habían logrado cooptar a buena parte de los medios en Chimbote, Casma y Huarmey, entre otras provincias. Sin embargo, esta dinámica no alcanzó a todos los medios de comunicación. Resaltan, por ejemplo, los diarios Correo y Diario Chimbote, las emisoras Radio Santo Domingo y Radio Católica, así como las estaciones televisoras Antena Norte, Real Televisión y Canal del Pueblo, cuya oposición al gobierno los convirtió en objeto de ataques frontales por parte de la maquinaria de Álvarez ${ }^{26}$.

Según los testimonios de los periodistas entrevistados, un sector se atrevió a manifestar sus críticas sobre la gestión en 2008. Como respuesta a esta situación, Álvarez optó por armar su propio aparato, conformado por periodistas y

\footnotetext{
23 Actualmente, en medio del proceso judicial, se han presentado pruebas que podrían implicar la complicidad de algunas de estas agencias en la impunidad que operó en la región. Es relevante mencionar que, hasta donde se ha podido conocer, la Policía Nacional del Perú tampoco fue muy receptiva o colaborativa en las investigaciones del Ministerio Público o del Poder Judicial, así como en el esclarecimiento de los crímenes relacionados al sicariato en la región, más aún cuando involucraban posibles motivaciones políticas.

24 Por ejemplo, el Módulo de Atención Chimbote de la Defensoría del Pueblo, liderado por Jealine Villanueva, tuvo un accionar precario durante esos años, ya que según las fuentes revisadas, la representante de la Defensoría en Chimbote mencionó que simplemente se hicieron algunas advertencias y recomendaciones para situaciones específicas, como es la seguridad ciudadana y el sistema de reclamos administrativos (Arévalo, 2014).

25 Durante el periodo de Álvarez, la programación de varios medios de comunicación consistía en la repetición ininterrumpida de spots publicitarios de las obras del presidente regional (Arévalo, 2015). Por otro lado, otros canales cumplían con las funciones de ataque y deslegitimación a la oposición, mientras que otros se limitaban a pasar videos musicales, evitando que los espacios sean tomados por la oposición.

26 Sin embargo, como Álvarez fue comprando varios de estos medios, el Canal 55 fue el último canal independiente que quedó. A su vez, de parte de los medios escritos, el Diario Correo, edición Chimbote, cumplió un rol importante al presentar entrevistas y hacer el seguimiento a algunos escándalos ocurridos durante la gestión de Álvarez.
} 
medios de comunicación que habrían trabajado directamente para su gestión. Es así como se crea "La Centralita», espacio antes mencionado, donde se habría conducido la estrategia de amedrentamiento a la oposición y creación de psicosociales. Además de ello, los testimonios recopilados indican que algunos corresponsales de medios nacionales podrían haber estado vinculados con los periodistas comandos, por lo que, durante mucho tiempo, estos solo pasaban noticias que favorecían al gobierno regional.

El quiebre de la gestión de Álvarez y la socialización del conflicto ocurrida en Áncash se produjo con la escandalosa muerte de Ezequiel Nolasco, situación que logró escalar a la discusión nacional e internacional y propició la caída de Álvarez. Estos episodios coincidieron con el inicio del proceso electoral 2014, donde Waldo Ríos, otra cuestionada figura política de la región, resultó electo como gobernador regional ${ }^{27}$. La principal estrategia de campańa de Ríos en aquellas elecciones fue la promesa de entregar 200 soles, del presupuesto proveniente del canon, a todos los ancashinos, oferta que, al no poder ser cumplida, generó protestas. De esta manera, sin una coalición o un aparato político sólido, al igual que su antecesor, Ríos afrontó una serie de denuncias por parte de sus opositores, relacionadas a presuntos actos de corrupción ocurridos durante su gestión como alcalde de Huaraz ${ }^{28}$.

De esta manera, puede verse que si bien la gestión de Álvarez destacó por encontrársele involucrado en distintos delitos y escándalos políticos, la misma dinámica de inestabilidad y debilidad, aunque con diferentes matices, continúa con la siguiente gestión. El caso ancashino demuestra que, bajo esas circunstancias, los grandes ingresos derivados del canon, junto con la poca fiscalización de las entidades del gobierno central, repercuten en la dinámica política regional, así como en la calidad de la democracia al mismo nivel. A diferencia de su antecesor, en ese sentido, las nuevas condiciones presupuestarias y de control ayudan a entender la imposibilidad de reproducción de las dinámicas previamente revisadas.

\footnotetext{
27 Ríos fue congresista durante el gobierno fujimorista y fue parte del grupo de personas que recibió dinero por parte de Vladimiro Montesinos para pasarse a las filas del fujimorismo.

28 Es por ese motivo que, a mediados de marzo de 2016, la región vivió serios momentos de incertidumbre política y administrativa, al darse a conocer una orden de captura para que el entonces gobernador regional vaya a declarar sobre los supuestos delitos cometidos en su gestión como alcalde de Huaraz. Esta situación solo propició que Ríos se encuentre prófugo durante algunos días. Finalmente, Waldo Ríos fue remplazado por su vicepresidente, Enrique Vargas.
} 


\section{LORETO: COALICIONES CONTRA EL GOBIERNO}

El 23 de julio de 2014, el gobernador de Loreto y candidato a la reelección, Yván Vásquez, dejó la clandestinidad y se entregó a la Policía Nacional del Perú en medio de un mitin proselitista. La captura se realizó en atención a una orden de prisión preventiva dictada unos días antes por su supuesta responsabilidad en una licitación irregular para la construcción de embarcaciones fluviales ${ }^{29}$. Años antes, la prensa regional ya había empezado a divulgar las acusaciones que sistemáticamente aparecían sobre problemas similares, como en el caso de las irregularidades en la construcción del sistema de Alcantarillado Integral de Iquitos. Esta situación se agravó cuando en el año 2014, a puertas de las elecciones regionales, distintas organizaciones y colectivos hicieron públicas estas denuncias con el objetivo de llamar la atención sobre estos procesos ${ }^{30}$.

Este contexto generó fuertes conflictos entre los seguidores de Vásquez y los grupos opositores, incluyendo algunos sectores de la prensa local, que en varios casos terminaron en enfrentamientos violentos y amenazas contra las vidas de los implicados. Al mismo tiempo, diferentes opositores políticos denunciaban que Vásquez orquestaba su tercera reelección desde el gobierno regional, buscando consolidar su hegemonía electoral ofreciendo recursos públicos y privados para atraer candidatos competitivos y aliados sociales transcendentales, pero también amedrentando a quienes se le opusieran. Sin embargo, fue especialmente luego de la sentencia y consecuente captura que los medios de comunicación nacionales empezaron a hacer eco de estas denuncias, concentrando su atención también en los «manejos autoritarios» de la gestión. Este enfoque se consolidó cuando la prensa nacional empezó a equiparar lo que acontecía en Loreto con otras regiones como Áncash.

A pesar de estas lecturas coyunturales, varias condiciones eran muy distintas en el caso loretano. Para empezar, la arena política estaba bastante más articulada en función de la disputa entre el movimiento político Fuerza Loretana (FL) de Yván Vásquez $^{31}$, y las demás fuerzas de oposición, entre las que resalta el Movimiento de

\footnotetext{
29 Esta sentencia fue dictada por la titular del Segundo Juzgado de Investigación Preparatoria de Loreto, haciendo eco del pedido de la Fiscalía Corporativa Especializada en Delitos de Corrupción de Funcionarios por el presunto delito de colusión agravada al beneficiar a una empresa en la licitación pública para la adquisición de cuatro embarcaciones fluviales valorizadas en casi S/.9 millones. Dichas embarcaciones, según señala la denuncia, habían empezado a construirse mucho antes de que los procesos de licitación fueran hechos públicos, por lo cual se presumía que el proceso había sido direccionado para favorecer a una empresa en particular (El Comercio, 2014b).

30 Varias situaciones motivaron esta decisión, sin embargo, las inundaciones que se registraron en la ciudad durante los primeros meses de la época de lluvias fueron un detonante en medio del debate sobre las irregularidades del sistema de alcantarillado.

31 La inscripción vigente de Fuerza Loretana data del año 2005, sin embargo, su historia se puede registrar desde el año 1998, participando en todas las elecciones subnacionales desde esa fecha. Adicionalmente, Fuerza Loretana
} 
Integración Loretana (MIL) de Fernando Meléndez, quien está actualmente en el cargo. Mientras que desde la sociedad, el Frente Patriótico, encabezado por Américo Menéndez, recuperaba cierto de grado de autonomía. Vásquez había accedido por primera vez al gobierno regional en las elecciones de 2006 con el $41 \%$ de votos válidos $^{32}$ y fue reelecto en 2010 con el $32 \%$. En este último proceso electoral, Meléndez, un ex funcionario regional del sector Educación, hizo su aparición con el MIL y quedó en cuarto lugar, obteniendo el 12\% de los votos válidos.

Tabla 2. Trayectoria electoral de Yván Vásquez

\begin{tabular}{|c|c|c|c|c|c|c|}
\hline Año & $\begin{array}{l}\text { Proceso } \\
\text { electoral }\end{array}$ & $\begin{array}{l}\text { Cargo al que } \\
\text { postuló }\end{array}$ & Organización política & Región & Provincia & Elegido \\
\hline 1990 & $\begin{array}{l}\text { Elecciones } \\
\text { generales }\end{array}$ & Diputado & $\begin{array}{c}\text { Movimiento } \\
\text { Regionalista Loreto }\end{array}$ & Loreto & & $\mathrm{NO}$ \\
\hline 1998 & $\begin{array}{l}\text { Elecciones } \\
\text { municipales }\end{array}$ & $\begin{array}{l}\text { Alcalde } \\
\text { provincial }\end{array}$ & Fuerza Loretana & Loreto & Maynas & SI \\
\hline 2002 & $\begin{array}{l}\text { Elecciones } \\
\text { regionales y } \\
\text { municipales }\end{array}$ & $\begin{array}{l}\text { Presidente } \\
\text { regional }\end{array}$ & $\begin{array}{c}\text { Movimiento } \\
\text { Independiente Fuerza } \\
\text { Loretana }\end{array}$ & Loreto & & $\mathrm{NO}$ \\
\hline 2006 & $\begin{array}{l}\text { Elecciones } \\
\text { generales }\end{array}$ & $\begin{array}{l}\text { Segundo vice- } \\
\text { presidente de } \\
\text { la República }\end{array}$ & Fuerza Democrática & Nación & & $\mathrm{NO}$ \\
\hline 2006 & $\begin{array}{l}\text { Elecciones } \\
\text { regionales y } \\
\text { municipales }\end{array}$ & $\begin{array}{l}\text { Presidente } \\
\text { regional }\end{array}$ & Fuerza Loretana & Loreto & & SÍ \\
\hline 2010 & $\begin{array}{l}\text { Elecciones } \\
\text { regionales y } \\
\text { municipales }\end{array}$ & $\begin{array}{l}\text { Presidente } \\
\text { regional }\end{array}$ & Fuerza Loretana & Loreto & & Sí \\
\hline 2014 & $\begin{array}{l}\text { Elecciones } \\
\text { regionales y } \\
\text { municipales }\end{array}$ & $\begin{array}{l}\text { Presidente } \\
\text { regional }\end{array}$ & Fuerza Loretana & Loreto & & $\mathrm{NO}$ \\
\hline 2016 & $\begin{array}{l}\text { Elecciones } \\
\text { generales }\end{array}$ & Congresista & Alianza Popular & Loreto & & $\mathrm{NO}$ \\
\hline
\end{tabular}

Fuente: Infogob, Jurado Nacional de Elecciones. Elaboración propia.

ha participado en dos elecciones nacionales, aunque sin éxito. La primera en 2006, en alianza formal con Fuerza Democrática, poniendo a Vásquez como candidato a la segunda vicepresidencia; mientras que la segunda, de manera informal dentro de la Alianza Popular junto con el Partido Aprista Peruano, el Partido Popular Cristiano y Vamos Perú, teniendo a Vásquez como candidato al Congreso de la República por Loreto (Fuente: Infogob).

32 Previamente, Vásquez fue electo como alcalde provincial de Maynas en 1998 y perdió las elecciones de 2002 siendo candidato al gobierno regional. 
Luego de los resultados, el MIL y su candidato continuaron con una campaña activa, a diferencia de los demás candidatos, perfilándose como una de las fuerzas más importantes de la oposición a Fuerza Loretana. De esta manera, los cuatro años de gestión de Vásquez fueron acompañados por cuatro años de crítica sistemática y campańa proselitista por parte del MIL. Estos esfuerzos encontraron tierra fértil en el descontento que la gestión empezaba a granjear en distintos frentes y que se había reflejado, tímidamente, en la reducción del caudal electoral de Fuerza Loretana. Este descontento no solo estaba presente en el electorado por las crecientes denuncias de mal manejo en los fondos públicos del GOREL, sino también en grupos de interés muy particulares que habían apoyado a la gestión de Vásquez, pero que con el tiempo se fueron realineando con la fuerza política opositora. Sin embargo, en el caso de los primeros, la gestión de Vásquez podía responder relativamente a las demandas particulares de los sectores sociales, especialmente los más vulnerables ${ }^{33}$, mientras que para los segundos la respuesta era más compleja en tanto los intereses eran, en muchos casos, excluyentes entre sí.

Por ello, aun cuando el gobierno regional logró establecer importantes nexos con distintas instancias de alcance nacional, el control de las fuerzas opositoras de la región era bastante más esquivo que en el caso ancashino ${ }^{34}$. En este escenario, algunos sectores del empresariado regional y del periodismo son particularmente importantes, aun cuando no estén completamente disociados. Es cierto que dentro de la región los periodistas son, por lo general, independientes en el sentido estricto del término, es decir, que desempeñan sus labores en términos estrictamente profesionales, antes que desarrollan una agenda política o económica propia. Sin embargo, en tanto, la mayor cantidad de medios de comunicación están en manos de empresarios y políticos con intereses bien definidos y con una línea editorial más o menos establecida, la cual, por cierto, va cambiando conforme lo hacen sus intereses. Por este motivo, los empresarios

\footnotetext{
33 Por ejemplo, al igual que en Áncash, el gobierno regional donó terrenos para la formación de asentamientos humanos con el objetivo de ampliar sus bases de apoyo. Este es el caso del asentamiento "Villa Pelacho", bautizado de esa manera en honor al apelativo de Vásquez. Testimonios recopilados en ese asentamiento humano y otros en Nauta e Iquitos coinciden en que, por lo general, la gestión de Vásquez era receptiva a sus demandas y a la creación de puestos temporales de trabajo en distintos rubros. Por otro lado, el gobierno regional desarrolló un programa social denominado "Techo digno», el cuál repartía, principalmente, planchas de calamina para las viviendas en los sectores económicamente más deprimidos. Algunos de los beneficiarios de este tipo de iniciativas constituyeron, posteriormente, las fuerzas de choque que defendían al gobierno regional de sus opositores en las manifestaciones públicas.

34 Según los testimonios de los periodistas, las fuerzas opositoras identificaban que los aliados del gobierno regional en el plano nacional no eran lo suficientemente fuertes como para blindarlo. Sus redes básicamente se componían por contados dirigentes nacionales del Partido Aprista y a algunos representantes parlamentarios de la región, entre los cuales identificaban a Víctor Isla y Normal Lewis, los mismos que aparentemente fungían como bisagra con otras instituciones y actores en ese nivel.
} 
locales son importantes en la dinámica política puesto que aportan con sumas de dinero para las campańas, pero también con sus medios de comunicación y, en algunos casos, bases de apoyo en las diferentes provincias ${ }^{35}$.

La dinámica empresarial, entonces, afecta tanto por su rol en el apoyo a las distintas fuerzas políticas, pero también por la expectativa que tiene para retribución de los favores de campaña. Además, es común escuchar entre las fuentes la referencia al ingreso de dinero proveniente de negocios que contravienen la legalidad, como el narcotráfico y la tala ilegal, los cuales serían canalizados por medio del financiamiento de campańas mediante espacios indirectos, especialmente relacionados con los rubros de servicios y construcción. Aunque es algo que no ha podido comprobarse, esta hipótesis es sugerente si es que tomamos en consideración la necesidad de recursos por la prolongación e intensidad de las campañas políticas de distintas fuerzas aún en épocas no electorales.

Así, los citados casos de corrupción parecerían tener origen en la dinámica de prebendas —o su incumplimiento- por parte de la gestión regional. Como hemos visto, una parte importante de las denuncias públicas de corrupción están relacionadas con licitaciones en la provisión de productos y servicios, así como en la construcción de infraestructura estatal. En algunos casos algunos de los empresarios fueron priorizados por sobre otros, mientras que en otros, la licitación priorizó a consorcios foráneos o extranjeros ${ }^{36}$. Así, aprovechando la molestia ciudadana, estos grupos activaron sus recursos mediáticos y políticos para enfrentarse entre ellos, acusándose de presuntas irregularidades en las licitaciones, pero también para presionar a la gestión en el cambio de prioridades. Por estos motivos, la gestión de Fuerza Loretana, perdiendo bases de apoyo en diferentes frentes a puertas de la campaña electoral, inició el despliegue de estrategias que fomentaban una mayor polarización, al mismo tiempo que buscaba cooptar los medios de comunicación locales de distintas maneras para hacer frente a la campaña contraria ${ }^{37}$.

\footnotetext{
35 Las fuentes consultadas señalaron que este tipo de dinámicas se podían observar en el acercamiento con Adela Jiménez, en ese entonces regidora de Maynas y luego candidata a la alcaldía. Jiménez no solo aportaba una base política considerable, sino que su cónyuge, un conocido empresario de la región, aseguraba también el apoyo de sus medios de comunicación. Una lógica similar parecería operar en la relación entablada con Lincoln Cornejo, empresario y propietario del diario La Región.

36 Así, por ejemplo, un ex funcionario del gobierno regional señalaba que la principal oposición al proyecto del Sistema Integral de Alcantarillado era la licitación a la empresa China International Water and Electric Corp. Era evidente, manifiesta, que la "gente no se la agarraba con la empresa porque era china", sino porque habían cuestionamientos a su modo de trabajo y el efecto que tenían las obras en la ciudad, pero quienes «metían el tema» tenían otros intereses. 37 La existencia de corrupción en estos casos no es materia central de esta investigación. Sin embargo, es importante señalar que las diatribas frente a la gestión se originaron por este tipo de licitaciones, pero también que Vásquez tuvo que afrontar procesos judiciales por estas acusaciones. En palabras de una de nuestras fuentes: «De que había corrupción, había. El problema era que no era para ti [la ciudadanía] esa corrupción».
} 
En ese sentido, es importante señalar que en la región también existe otro tipo de medios de comunicación, independientes de los poderes empresariales, que funcionan como emprendimientos o negocios en los que opera otra forma de lucro. Estos medios de comunicación, especialmente radiales y televisivos, por lo general, funcionan mediante el arrendamiento de espacios para periodistas, quienes invierten dinero, directamente o por financiamiento de terceros. En ese sentido, un espacio radial o televisivo se capitaliza para ser explotado por los dueños de las radios o televisoras, o por los periodistas que los arriendan, haciéndolos económicamente "productivos» mediante acusaciones o campañas a favor de diferentes actores políticos, de acuerdo al acceso a recursos por medio de publicidad contratada, oportunidades laborales o sobornos.

En este escenario, los periodistas hacen las veces de piezas intercambiables entre las diferentes fuerzas políticas. Muchos de ellos son cooptados con sueldos, con espacios en medios de comunicación o con puestos en la función pública ${ }^{38}$. Tomando esto en consideración, las acusaciones de cooptación y amedrentamiento a la prensa se correspondían con la compra de espacios para colocar programas con líneas afines a la gestión, pero también para dejar a los periodistas críticos sin espacios. A pesar de ser una práctica bastante extendida en las regiones, en el caso de Loreto resalta por la poca discreción en los movimientos y estrategias que desarrollan los diferentes actores para hacer avanzar sus prerrogativas, pero también por la existencia de distintos frentes pugnando por el acceso a estos espacios. En el largo plazo, como veremos, estas relaciones reproducen y exacerban problemas relativos al financiamiento de campañas, contribuyendo a socavar la gobernabilidad y la representación política.

Este escenario cambiante nos ayuda a comprender la caída de Vásquez tras las acusaciones de corrupción y la posterior victoria del MIL en las elecciones de 2014, con el 41,28\% de los votos frente al 28,05\% de Fuerza Loretana. Como hemos señalado, esto es visto como el fruto de una campaña que inició el día siguiente a las elecciones de 2010 con una postura crítica frente a la gestión ${ }^{39}$,

\footnotetext{
38 Las fuentes señalan que varios periodistas se acomodaron bajo esta dinámica con Fuerza Loretana y, posteriormente, pasaron a tener una posición completamente distinta, en radical oposición a la gestión. Se seńala, además, que algunos de ellos habrían terminado siendo operadores políticos del MIL en la campańa, siendo luego recompensados con publicidad o puestos en el GOREL en la actual gestión. Similares denuncias contra dirigentes sociales aparecieron en medios regionales como Pro y Contra, especialmente en el caso del Frente Patriótico que era acusado de, una vez más, haber sido cooptado por el gobierno regional, esta vez bajo Meléndez.

39 Algunas fuentes concuerdan en que esta campańa fue posible por la presunta presencia de dinero proveniente de la familia de la esposa de Meléndez, vinculados al gobierno fujimorista en la década de 1990. Su suegro, Cirilo Torres Pinchi, fue funcionario de la Dirección Regional de Educación durante esta época y fue denunciado por la presunta malversación de fondos en esta oficina pública, aunque, hasta la actualidad, no se ha puesto a derecho ante la justicia (Pro y Contra, 2014). Estas versiones tuvieron eco en algunos medios nacionales como La República (La República, 2013), pero no han logrado ser probados.
} 
pero también mediante la constitución de alianzas con grupos empresariales y políticos locales, tanto aquellos que ya eran opositores, como los que no vieron cumplidas sus distintas expectativas por parte de la gestión. En ese sentido, más allá de la construcción de un régimen autoritario subnacional, lo que observamos es la rearticulación de coaliciones dentro del sistema político loretano. Esta situación motivó una estrategia reactiva poco exitosa, aunque con efectos reales sobre el pluralismo y la competencia política, que fue contestada por la coalición opositora.

Esto explica, hasta cierto punto, por qué varios de estos fenómenos no cesaron con la caída de Fuerza Loretana y la nueva gestión del MIL. Particularmente porque las coaliciones formadas para contestar a la gestión de Vásquez se deterioraron aceleradamente. Esto se explica por varios motivos, entre los que resaltan las aspiraciones políticas de algunos de los otrora aliados, la priorización de determinadas agendas sobre otras, así como la incapacidad de priorizar proyectos de inversión por la reducción del presupuesto regional como producto de las reformas en la distribución del canon. Esto ha llevado al enfrentamiento entre distintos empresarios que compiten por la provisión de servicios al GOREL, pero también a que varios de los grupos realineen sus estrategias respecto a la gestión del MIL, aunque no en las proporciones de confrontación experimentadas por Fuerza Loretana ${ }^{40}$.

\section{Conclusiones}

Luego de la revisión de los casos, podemos reafirmar la conclusión de que la calidad y la forma de la democracia no se agota en la fórmula nacional, sino que es importante ver también su configuración y matices en las instancias locales (Stokes y Amaral, 2005, p. 11). Esto, sin embargo, excepcionalmente llega a escalar al punto de constituir regímenes políticos diferenciados, especialmente de corte autoritario. Por lo menos en el nivel regional, este parece ser un hecho centrado únicamente en la experiencia de Áncash, donde una serie

\footnotetext{
40 A inicios de 2015, esta dinámica había sido trasladada a los medios de comunicación. El alquiler de Radio Diez y la reestructuración del canal UCV Satelital, propiedad del consorcio de César Acuńa, mostraban la pugna por cooptar medios de comunicación por parte del grupo cercano a Meléndez para avanzar intereses particulares y contrarrestar los efectos de los medios de sus otrora aliados. En ese escenario, la estrategia usada fue el alquiler del medio o negociación de la programación para hacerse con el control y, según algunos testimonios, poner gente afín a la gestión o retirar elementos potencialmente contrarios como los periodistas James Beuzeville, quien fue retirado de Radio Diez, y Jaime Vásquez, a quien originalmente habían propuesto para hacerse cargo de UCV Satelital. El resultado de este intento de cooptación fue una polarización importante en los diferentes medios de comunicación que funcionan como trincheras para la defensa y ataque de consignas particulares.
} 
de condiciones permiten la formación o perversión de las reglas informales de gobierno y competencia hasta ese nivel. En el caso de Loreto, por ejemplo, no se encuentra una dinámica similar. En ese sentido, es claro que los dos casos son diferentes en los resultados y que dicha divergencia se explica en función de consecuentes diferencias en las condiciones que luego resumiremos.

Sin embargo, una mirada más amplia, más allá de la centralidad de la competencia electoral, nos lleva a afirmar que, aún en sus diferencias, ambos casos son parte de un mismo fenómeno, puesto que sus sistemas políticos no son enteramente democráticos. Si nos centramos en el componente electoral, es claro que existen dos presidentes regionales que buscan permanecer en el poder y para ello despliegan estrategias de convencimiento y dominación sobre la población pero en intensidades y alcances diferentes ${ }^{41}$. Sin embargo, en ambos espacios existen actores sociales que, más allá de las elecciones, pugnan por la concentración de poder en la región para satisfacer intereses particulares de distintos tipos. En ambos casos, dichos actores pueden, en la práctica, extender su poder por encima o fuera del alcance de las reglas establecidas por el Estado, el régimen y, hasta cierto punto, la sociedad. Son actores capaces de actuar, potencialmente, de legibus solutus (O’Donnell, 2007, p. 33), aunque no en solitario ni de forma latente ${ }^{42}$.

Por consiguiente, lo democrático o autoritario no se limita a la arena electoral. En estos casos, estas dinámicas no se despliegan como estrategias de acceso al poder o de reelección, sino sobre todo como una de ejercicio de poder, ya sea para avanzar intereses particulares o para mantener el gobierno (ver Mazzuca, 2007). Esto no quiere decir que no exista un interés electoral, sino que las estrategias de clientelismo, cooptación y amedrentamiento no están circunscritas únicamente a ese propósito. En estos casos, en particular, las estrategias clientelares están concentradas en los sectores más deprimidos de la región, pero generalmente en zonas urbano-marginales ${ }^{43}$; sin embargo, el objetivo tiene

\footnotetext{
41 Esto, sobre todo, en el caso de Loreto donde el gobernador fue incapaz de instaurar un modelo similar al de Áncash.

42 Aquí hay un punto importante en disputa, puesto que las estrategias y objetivos son muy distintos entre los actores antes reseñados, situación que repercute en los niveles de violencia e irrespeto sobre los derechos humanos, especialmente de ciudadanos y políticos. Es claro que la dinámica de violencia en Áncash hace más fácil la categorización del caso como autoritarismo subnacional, aún bajo los parámetros estrictamente del régimen político. Esto, por otro lado, es más complicado en el caso de Loreto, puesto que no solo el gobierno regional no fue capaz de establecer un modelo similar al ancashino, sino que la distribución del poder alcanza también a los actores sociales que juegan como aliados y rivales en distintos momentos. Aun sin violencia, estos actores corroen las bases de la democracia, especialmente en función de la representación y respuesta del gobierno frente a la ciudadanía.

43 Expresadas fundamentalmente en el obrismo (Muñoz, 2016), el patronazgo y políticas de redistribución de distinto tipo, tales como el acceso a terrenos controlados por el gobierno o la ausencia de represión frente a invasiones o actividades informales e ilegales (ver Holland, 2014; Collier, 1978). La literatura sugiere que las distintas estrategias
} 
más relación con la estabilidad del gobierno antes que con el aseguramiento de las elecciones ${ }^{44}$.

Aun en contextos federales, la presencia y capacidad de las instituciones y agencias nacionales dentro de las regiones repercute en el desarrollo de las instituciones y las relaciones dentro de las mismas. Por consecuencia, la formación, dinámica y estabilidad del enclave subnacional no solo depende de elementos internos, sino también de cómo los funcionarios locales lograron calar a nivel nacional (Gibson, 2012, p. 5), o, dicho a contrario, de cuánto y cómo los actores de este nivel están dispuestos a intervenir en las dinámicas subnacionales para solucionar los problemas antes reseñados.

Esto es posible, en el caso de países federados con partidos fuertes, gracias a la canalización de la influencia hacia el nivel nacional mediante la existencia y relación con un partido hegemónico (Gibson, 2012, p. 28). Sin embargo, en países unitarios, más aún en un contexto de debilidad partidaria como el peruano (Meléndez, 2004; Zavaleta, 2014), estas relaciones son más inconsistentes debido a que dependen de políticos individuales o redes inestables de funcionarios en el nivel central.

Tal como advierte la experiencia comparada, detrás del poder e influencia del político subnacional, se encuentra una red de legisladores con acceso a los diferentes aparatos estatales de control y agencias de gobierno a nivel nacional (O’Donnell, 1999; Calvo y Leiras, 2010). Esa dinámica, sin embargo, no es unidireccional, el político a nivel subnacional puede ofrecer votantes y recursos para la campańa, o la gobernabilidad del territorio, especialmente cuando se trata de un espacio de extracción de recursos (Arévalo, 2014). No obstante, para los actores regionales, la influencia fuera de la región también puede ser considerada como arma de doble filo. Como sustenta Gibson, cuando los políticos subnacionales se vuelven líderes observables desde instancias nacionales, las tensiones al interior de su territorio pueden nacionalizarse con mayor facilidad y convertirse en una amenaza para el mantenimiento del enclave (Gibson, 2012, pp. 28-29). En el caso peruano esta doble dimensión es fundamental

\footnotetext{
clientelares desplegadas generalmente están concentradas en los sectores que son percibidos como más proclives a establecer vínculos con el gobernante (Kitschelt y Wilkinson, 2008, pp. 12-13). Asimismo, ejecutar el gasto público supone que exista la capacidad de responder a las diferentes necesidades y presiones, enfatizando la ejecución de los programas sustantivos que corresponden a diferentes grupos en la sociedad (Ames, 1977, pp. 151-152).

44 Cuando Gibson estudia el caso argentino de autoritarismo subnacional en la provincia de Santiago de Estero, recuerda que los mecanismos de patronazgo público son cruciales para instalar la disciplina al régimen (2012: 102). Así, cuando el clientelismo y el control institucional de la oposición no son suficientes, el patronazgo puede llenar ese vacío (Gibson, 2012, p. 103).
} 
para entender la permisibilidad ante la formación de este tipo de enclaves autoritarios, y, al mismo tiempo, la caída de los mismos ${ }^{45}$.

En un país unitario como el Perú, y esta es quizás la distinción más importante con los países federales, las estrategias desplegadas por estos actores se tornan insostenibles una vez que se activan los mecanismos de control político, administrativo o económico desde el Estado central. Esto es particularmente importante en un contexto de desinstitucionalización política, donde la articulación vertical entre gobernadores y congresistas es circunstancial y funcional, por lo que es más difícil observar una dinámica negociada con el gobierno a cambio de votos en el Parlamento, por ejemplo (ver Rebolledo, 2012). Una vez activados los mecanismos de control y «cortados» los suministros fiscales — como sucedió en el Perú-, los gobernadores son incapaces de constituir sus propias reglas de juego formales ni de procurar ingresos propios o, finalmente, de extender sus redes de influencia a toda la institucionalidad de control nacional del Estado; sin embargo, el sistema político que dio forma al conflicto no se extingue por completo ${ }^{46}$.

En ese sentido, la existencia de coaliciones sociales o políticas es un componente significativo en la dinámica de poder regional en los términos antes reseñados ${ }^{47}$. En el caso de Áncash, resulta claro que la actividad económica más importante es la minería, la cual está concentrada en una empresa privada de carácter nacional. Los demás sectores, como el pesquero, han perdido influencia o desarrollan actividades igualmente engarzadas con empresas nacionales y trasnacionales. En ese sentido, si bien el gobierno regional no tiene coaliciones importantes que puedan oponérsele, tampoco tiene aliados regionales que puedan asegurar su estabilidad ante las tensiones propias de la competencia política. En ese sentido, controlando un presupuesto elevado, el

\footnotetext{
45 Esto se ilustra claramente con la caída de Álvarez luego del escandaloso asesinato de Nolasco, así como el efecto que esto tuvo en la permanencia de otros presidentes regionales una vez que el tema se hizo de dominio público a nivel nacional.

46 La prohibición de la reelección ha limitado efectivamente el surgimiento de este tipo de caudillos y que permanezcan como autoridades subnacionales a largo plazo, con la excepción del Callao, donde la organización política ha resuelto parcialmente los problemas de sucesión (ver Rojas, 2016). Sin embargo, los actores sociales y los incentivos que configuraron estas dinámicas originalmente no han desaparecido por completo. Como hemos visto en el caso de Áncash y Loreto, la inestabilidad y la pugna por el poder en tiempos no electorales se mantiene, aunque su atención se reconfigura.

47 De esta manera, a tono con Gervasoni (2010), los recursos extraordinarios del canon funcionan en el caso de Áncash como fuentes de poder desestabilizadoras en función del gobernador regional (Arévalo, 2014; Cueva et al., 2016), mientras que en el caso de Loreto su importancia explicativa reside, más bien, en que su uso es una de las fuentes de disputa que antagoniza a las fuerzas regionales. De esta manera, el efecto del «boom fiscal» en las regiones tiene direcciones e intensidades divergentes. De hecho, en regiones como Cusco, la que más se ha beneficiado comparativamente de este tipo de recursos, no se observan ninguno de estos impactos sino, por el contrario, como «maldición de recursos» en contra de la institucionalidad regional (ver Crabtree, 2013).
} 
gobierno regional no solo asegura su gobernabilidad echando mano de estos recursos para desplegar estrategias clientelares, sino que aprovecha esta ventaja para consolidar su poder mediante estrategias más represivas ${ }^{48}$.

En el caso de Loreto, por otro lado, los sectores económicos regionales son relevantes para comprender la forma cómo se configura y realinea el sistema político, utilizando otros actores sociales y políticos para encuadrar los conflictos. Por un lado, los empresarios formales e informales participan de las campańas mediante la provisión de recursos financieros, administrativos y proselitistas ${ }^{4}$. En ese sentido, ciertos grupos de interés económicos despliegan su apoyo político como parte de un comportamiento pragmático, en función de las licitaciones y «favores» que pueden obtener del gobierno regional. Esta situación afecta tanto la gobernabilidad democrática como la representación política, debido a que las gestiones regionales deben procurar responder a estos intereses de diferentes maneras. Estas dinámicas se tornan más tensas con la introducción de inversión foránea, especialmente en provisión de servicios y construcción de infraestructura, pero sobre todo con la reducción de recursos económicos en la gestión regional, lo que motiva que estas estrategias sean más evidentes.

Esto, sin embargo, sucede sin que estos actores se constituyan como parte de una élite regional (ver Muñoz et al., 2016), sino de forma muy fragmentaria, hasta conflictiva, y precisamente por su inexistencia. En estos casos, como hemos visto, esto es potenciado por el hecho de que los medios de comunicación regionales dependen de grupos empresariales o están a su disposición económica para hacer eco de los intereses del gobierno o silenciar a sus contrincantes ${ }^{50}$. En el caso de Loreto, el gobierno tiene que competir con los demás grupos por el control de estos espacios, mientras que en Áncash los recursos antes mencionados, sumado a la debilidad de la oposición, hacen que sea

\footnotetext{
48 Una nota aparte requiere el acceso a recursos e infraestructura para llevar a cabo estas estrategias. Por un lado, como hemos mencionado, existe una creciente actividad criminal en la costa norte del país, de la que Chimbote hace parte (ver IDL, 2015). Como sostiene Meléndez «la región forma parte de un corredor de inseguridad [...] Crecimiento económico e informalidad permiten el arraigo de estos poderes ilegales. Existe, pues, una disponibilidad de criminales a sueldo» (Peru21, 2014). Por otro lado, falta aún más estudio sobre el «reciclaje» de la infraestructura creada y potenciada durante el Perú de la década de 1990 alrededor del Servicio de Inteligencia Nacional (SIN) de Vladimiro Montesinos. No solo las prácticas, sino sobre todo el expertise, llama la atención sobre la "disponibilidad» de recursos tecnológicos y humanos para el despliegue particular de este tipo de actividades (ver Mujica, 2014).

49 En esta dinámica aparecen también recursos provenientes de los sectores ilegales; sin embargo, su influencia no es directa, sino a través de actividades que hacen parte del sistema formal y, por lo tanto, son difíciles de rastrear (ver Durand, 2016). Aproximaciones importantes pueden encontrarse en Romero (2014) para el caso de Loreto, así como López (2014) y Canseco (2016) para otros casos.

50 En algunos casos esto se expresa mediante la primacía de los intereses de los propietarios o de aquellos que financian espacios y periodistas, censurado a periodistas que contravienen estos intereses; mientras que, en otros casos, cuando estas dinámicas no son posibles o hay una asimetría de recursos, se recurre al amedrentamiento directo.
} 
mucho más fácil para el gobierno el aseguramiento de este frente ${ }^{51}$. Al margen del tipo de maniobra empleada, esta situación repercute en la gobernabilidad, pero sobre todo en la representación de intereses y el acceso a fuentes de información libre, de calidad y plural por parte de la ciudadanía.

En resumen, estos escenarios tienen ciertamente un impacto en agravar las ya existentes deficiencias en la calidad de la democracia peruana en espacios subnacionales. Sin embargo, lo sustantivo de estos fenómenos no se halla solamente en la dinámica de competencia, sino sobre todo en los cambios fluidos en las dinámicas propias de los sistemas políticos regionales. En ambos casos, observamos que la condición inmediata para el surgimiento de una dinámica autoritaria está basada en la ausencia o pérdida de apoyo de la coalición gobernante, aunque con resultados divergentes. El contraste se encuentra en las características de los distintos sistemas políticos subnacionales, las cuales parecen haber sido formadas a lo largo de su experiencia histórica, dando origen tanto a grupos particulares como reglas informales que articulan sus relaciones ${ }^{52}$. Esto, sin embargo, es una primera aproximación a un tema ciertamente complejo que, por lo mismo, demanda mayor atención histórica y comparativa. Por lo pronto, el campo está abierto para estudios que profundicen este debate desde diferentes perspectivas analíticas.

\section{BibLIOGRAFÍA}

Ames, B. (1977). The Politics of Public Spending in Latin America. American Journal of Political Science, 21(1), 149-176. doi: 10.2307/2110453

Aragón, J. y Incio, J. L. (2014). La reelección de autoridades regionales y municipales en el Perú, 2006-2014. Revista Argumentos, 8(5), 16-30.

Arévalo, R. (2014). La dinámica politica a nivel subnacional: La estabilidad en la gestión de César Álvarez (2006-2013). Tesis de Licenciatura en Ciencia Política y Gobierno, Pontificia Universidad Católica del Perú, Lima, Perú.

Arévalo, R. (2015). ¿Cuento contigo? La estabilidad en la gestión de César Álvarez (2006-2013). Politai Revista de Ciencia Politica, 6(11), 111-125.

Barrenechea, R. (2014). Becas, bases y votos: Alianza para el Progreso y la política subnacional en el Perú. Lima, Perú: Instituto de Estudios Peruanos.

Barrenechea, R. y Sosa, P. (2014). Perú 2013: La paradoja de la estabilidad. Revista de Ciencia Política, 34(1), 267-292. doi: 10.4067/S0718-090X2014000100013

\footnotetext{
51 En otras regiones, por el contrario, el periodismo local funciona de forma más individualizada, siendo los periodistas quienes arriendan espacios o fundan sus propios medios de comunicación con el objetivo de avanzar sus propios intereses políticos —electorales o de agenda regional—o económicos, beneficiándose de la publicidad voluntaria o cooptada de las agencias públicas (Sosa Villagarcia, s/f).

52 La diferencia en las magnitudes de estas dinámicas, en ese sentido, puede rastrearse en las características propias de estos sistemas, las cuales por lo general trascienden a hechos coyunturales o a cambios recientes que pueden generar asimetrías de poder (Sosa Villagarcia, 2016).
} 
Behrend, J. (2012). Democratización subnacional: algunas pregunta teóricas. Postdata, 17(2), 11-34. doi:10.1353/jod.2016.0023

Behrend, J. y Whitehead, L. (2016). The Struggle for Subnational Democracy. Journal of Democracy, 27(2), 155-169.

BTI-Bertelsmann Transformation Index (2016). Peru Country Report. Gütersloh, Alemania: Bertelsmann Stiftung.

Calvo, E. y Leiras, M. (setiembre, 2010). Compañero, Correligionario, Comprovinciano. Initial notes on the nationalization of legislative collaboration. Documento presentado en la $106^{\circ}$ Reunión Anual de la Asociación Americana de Ciencia Política (APSA), Washington DC, Estados Unidos.

Canseco, F. (2016). Implementación de la Ley Forestal de Flora y Fauna Silvestre 27308: el caso de Ucayali en el periodo 2011-2014. Tesis de Licenciatura en Ciencia Política y Gobierno. Pontificia Universidad Católica del Perú, Lima, Perú.

Collier, D. (1978). Barriadas y élites: de Odría a Velasco. Lima, Perú: Instituto de Estudios Peruanos.

Córdoba, B. e Incio, J. L. (2013). La ventaja del incumbente en el ámbito subnacional: un análisis de las dos últimas elecciones municipales en Perú. Papel político, 18(2), 415-436.

Crabtree, J. (2013). Uso y abuso del sistema de canon en el Gobierno Regional del Cusco. Lima, Perú: Propuesta Ciudadana y Centro Bartolomé de las Casas.

Cueva, C., Chávez, N., Encinas, D. y Ramírez, M. (2016). Democracia y territorio en países unitarios. Una agenda de investigación pendiente. Lima, Perú: Jurado Nacional de Elecciones.

Durand, J.F. (2016). El que puede, puede: dinámicas informales e ilegales en los espacios rurales. En J. Durand, J. Urrutia y C. Yon (eds.), Perú: El problema agrario en debate. SEPIA XVI (pp. 21-86). Lima, Perú: Seminario Permanente de Investigación Agraria.

Eaton, K. (2015). Disciplining Regions: Subnational Contention in Neoliberal Peru. Territory, Politics, Governance, 3(2), 124-146. doi: 10.1080/21622671.2015.1005126

Gervasoni, C (2010). A Rentier Theory of Subnational Regimes: Fiscal Federalism, Democracy, and Authoritarianism in the Argentine Provinces. World Politics, 2(62), 302-340. doi : 10.1017/ S0043887110000067

Gervasoni, C. (2016). The Dimensions of Democratic and Hybrid Subnational Regimes: Evidence from an Expert Survey in Argentina. En J. Behrend y L. Whitehead (eds.), Illiberal practices: Territorial Variance Within Large Federal Democracies (pp. 120-161). Baltimore, MD: The Johns Hopkins University Press.

Gibson, E. L. (2010). Politics of the Periphery: An Introduction to Subnational Authoritarianism and Democratization in Latin America. Journal of Politics in Latin America, 2(2), 3-12.

Gibson, E. L. (2012). Boundary Control, Subnational authoritarianism in Federal Democracies. doi: $10.1017 / \mathrm{CBO} 9781139017992$

Gibson, E. L. y Calvo, E. (2000). Federalism and Low-Maintenance Constituencies: Territorial Dimensions of Economic Reform in Argentina. Studies in Comparative International Development, 35(3), 32-55. doi: 10.1007/BF02699765

Grupo Propuesta Ciudadana (2016). Los ingresos por canon y regalías en tiempos de crisis. Generación, distribución y transferencias. Lima, Perú: Grupo Propuesta Ciudadana.

Holland, A. (2014). The Distributive Politics of Enforcement. American Journal of Political Science, 59(2), 357-371. doi: 10.1111/ajps.12125

IDL-Instituto de Defensa Legal (2015). Seguridad ciudadana. Informe anual 2015. Balance del gobierno de Ollanta Humala: un quinquenio sin cambios sustanciales. Lima, Perú: IDL.

Kapiszewski, D., MacLean, L. M. y Read, B. L. (2015). Field Research in Political Science: Practices and Principles. doi:10.1017/CBO9780511794551

Kitschelt, H. y Wilkinson, S. I. (2008). Patrons, Clients and Policies: patterns of democratic accountability and political competition. doi: 10.1017/cbo9780511585869 
López, N. (2014). Los discursos políticos de las autoridades municipales sobre la hoja de coca en los distritos de Kimbiri y Pichari 2006-2010. Revista de Ciencia Política y Gobierno, 1(1), 157-178.

Manzetti, L.y Wilson, W. (2009). Why do Corrupt Governments Maintain Public Support. En C. Blake y S. Morris (eds.), Corruption and democracy in Latin America (pp. 77-93). Pittsburgh, PA: University of Pittsburgh Press.

Mazzuca, S. (2007). Reconceptualizing Democratization: Access to Power versus Exercise of Power. En G. Munck (ed.), Regimes and Democracy in Latin America: Theories and Methods (pp. 39-49). Nueva York, NY: Oxford University Press.

Meléndez, C. (2004). ¿Una descentralización sin partidos? El primer año de gestión del APRA en el gobierno regional de San Martín. Lima, Perú: Instituto de Estudios Peruanos.

Mujica, J. (2014). La desactivación del Servicio de Inteligencia Nacional. De la salida del personal de inteligencia al desarrollo de las agencias privadas de inteligencia en el Perú. Revista de Ciencia Política y Gobierno, 1(2), 129-155.

Muñoz, P. (2014). An Informational Theory of Campaign Clientelism: The Case of Peru. Comparative Politics, 47(1), 79-98. doi: 10.5129/001041514813623155

Muñoz, P. (2016). Estado, clientelismo y partidos políticos. Una perspectiva comparada. En R. Grompone (ed.), Incertidumbres y distancias: el controvertido protagonismo del Estado en el Perú (pp. 283-334). Lima, Perú: Instituto de Estudios Peruanos.

Muñoz, P., Monsalve, M., Guibert, Y., Guadalupe, C. y Torres, J. (2016). Élites regionales en el Perú en un contexto de boom fiscal: Arequipa, Cusco, Piura y San Martín (2000-2013). Lima, Perú: Universidad del Pacífico.

O’Donnell, G. (1999). On the State, Democratization, and Some Conceptual Problems: A Latin American View with Glances at Some Postcommunist Countries. En G. O'Donnell (ed.), Counterpoints: Selected Essays on Authoritarianism and Democracy (pp. 133-157). Notre Dame, IN: University of Notre Dame Press.

O'Donnell, G. (2004). The Quality of Democracy: Why the Rule of Law Matters. Journal of Democracy, 15(4), 32-46. doi : 10.1353/jod.2004.0076

O’Donnell, G. (2007). Democratic Theory and Comparative Politics. En G. O’Donnell (ed.), Dissonances: Democratic Critiques of Democracy (pp. 1-48). Notre Dame, IN: University of Notre Dame Press.

Palomino, M., Cerna, D. y Ríos, M. (2013). El servidor municipal: Un tema de agenda pendiente para fortalecer la gestión local. Revista Argumentos, 6(2), 38-44.

Rebolledo, J. (2012). Voting with the Enemy: A Theory of Democratic Support for Subnational Authoritarians. Tesis de Doctorado, Yale University, New Haven, Estados Unidos.

Remy, M. I. (2010). Crecientes distancias entre la política nacional y la política regional. Revista Argumentos, 3(5), 2-9.

Rojas, J. C. (2016). Construyendo estabilidad y éxito en una democracia sin partidos: El caso de Chim Pum Callao. Lima, Perú: Universidad Antonio Ruiz de Montoya.

Romero, E. (2014). Industria maderera y redes de poder regional en Loreto. Revista Argumentos, $8(3), 27-33$.

Sartori, G. (2011). Malformación de los conceptos en política comparada. En G. Sartori (ed.), Cómo hacer ciencia política: Lógica, método y lenguaje en las ciencias sociales (pp. 27-80). Madrid, España: Taurus.

Snyder, R. (2001). Scaling Down: The Subnational Comparative Method. Studies in Comparative International Development, 2(1), 93-110. doi : 10.1007/BF02687586

Sosa Villagarcia, P. (2016). Recursos, territorio, y coaliciones: Una aproximación Subnacional a la expansión del Estado peruano. Documento presentado en el XXXIV Congreso de la Asociación de Estudios Latinoamericanos (LASA). Nueva York, Estados Unidos. 
Sosa Villagarcia, P. (s/f). Espacios contratados: Periodismo local en tiempos de bonanza fiscal. Manuscrito inédito.

Stokes, S. y Amaral, A. (2005). Democracia local: clientelismo, capital social e innovación política en la Argentina. Buenos Aires, Argentina: Universidad Nacional de Tres de Febrero.

Vergara, A. (2015). La danza hostil: Poderes subnacionales y Estado central en Perú y Bolivia. Lima, Perú: Instituto de Estudios Peruanos.

Zárate, P. (2003). La democracia lejos de Lima: descentralización y política en el departamento de San Martín. Lima, Perú: Instituto de Estudios Peruanos.

Zas Friz, J. (2004). El actual proceso peruano de descentralización: balance y perspectivas de su diseño normativo e institucional. Lima, Perú: Grupo Propuesta Ciudadana.

Zavaleta, M. (2014). Coaliciones de independientes: Las reglas no escritas de la politica electoral. Lima, Perú: Instituto de Estudios Peruanos.

\section{Fuentes oficiales}

Ley $\mathrm{N}^{\circ}$ 27683. Ley de elecciones regionales. En: Diario Oficial El Peruano, 15 de marzo de 2002.

Ley $N^{\circ} 30305$. Ley de reforma de los artículos $191^{\circ}, 194^{\circ}$ y $203^{\circ}$ de la Constitución Política del Perú sobre denominación y no reelección inmediata de autoridades de los gobiernos regionales y de los alcaldes. En: Diario Oficial El Peruano, 10 de marzo de 2015.

Jurado Nacional de Elecciones. (2017). Infogob: Observatorio de la gobernabilidad - sistema de consulta en línea. Recuperado de http://www.infogob.com.pe/.

\section{Fuentes periodísticas}

Cardoza, Patricia (23 de marzo de 2014). Levitsky: En Áncash la democracia ya no existe. Correo (Edición Chimbote), p. 12.

Alcántara, Miguel (22 de mayo de 2015). Sánchez Milla ofrece entregar pruebas. Correo (Edición Chimbote), p. 9.

Redacción El Comercio (13 de julio de 2010). Asesinaron a encargado de la presidencia regional de Ancash. El Comercio, p. A28.

Redacción El Comercio (16 de marzo de 2014a). Sicarios matan a balazos a ex consejero regional de Áncash. El Comercio, p. A23.

Redacción El Comercio (19 de julio de 2014b). Dictan 18 meses de prisión preventiva para Yván Vásquez. El Comercio, p. A26.

La República (21 de julio del 2010). Sicarios dejan grave a consejero Nolasco. La República (Edición Norte).

La República (29 de octubre de 2013). Cinco candidatos alistan campaña para elecciones en Región Loreto. La República.

Meléndez Carlos (25 de marzo de 2014). Áncash SOS. Peru21.

Peru21 (25 de setiembre de 2012). Denuncian sobrevaloración en la compra de patrulleros en Áncash. Peru21.

Pro y Contra (7 de setiembre de 2014). El operador de Cirilo en el mil. Pro y Contra.

Bajak, Frank 14 de abril de 2014). Peru state branded a violent mini-dictatorship. Buenos Aires Herald. Recuperado de: http://www.buenosairesherald.com/article/156984/ peru-state-branded-a-violent-

Dube, Ryan (16 de mayo de 2014). Peruvian Regional President Suspected in Murder of a Rival. The Wall Stree Journal. Recuperado de: https://www.wsj.com/articles/ peruvian-regional-president-suspected-in-murder-of-a-rival-1400271112

Uceda, Ricardo (abril de 2014). La Región Bomba. Revista Poder. 